\title{
Collaborative stepped care is effectief bij angststoornissen
}

\author{
Samenvatting \\ Muntingh ADT, Van der Feltz-Cornelis CM, Van Marwijk HWJ, Spinhoven \\ Ph, Assendelft WJJ, De Waal MWM, Van Balkom AJLM. Collaborative \\ stepped care is effectief bij angststoornissen. Huisarts Wet \\ 2014;57(17):566-70.
}

ACHTERGROND Angststoornissen komen veel voor en zijn vaak chronisch. Er zijn effectieve, evidence-based behandelingen beschikbaar voor de basis-GGZ, maar binnen de huisartsenpraktijk blijkt het lastig om bij zo'n kortdurende behandeling rekening te houden met het chronische karakter van angststoornissen. Hier kan het 'collaborative stepped care model' uitkomst bieden.

METHODE In een clustergerandomiseerd onderzoek vergeleken we collaborative stepped care met de gebruikelijke zorg in de Nederlandse huisartsenpraktijk. We randomiseerden 31 praktijkondersteuners geestelijke gezondheidszorg ( $\mathrm{POH}-\mathrm{GGZ}$ ), werkzaam in 43 praktijken. De helft van de POH's-GGZ en de huisartsen kreeg een training in collaborative stepped care, de andere helft leverde de gebruikelijke zorg. De interventie bestond uit drie behandelstappen: begeleide zelfhulp, kortdurende cognitieve gedragstherapie en antidepressiva. De POH-GGZ voerde de interventies uit in samenwerking met de huisarts en een consulent-psychiater die advies kon geven tijdens de behandeling. De POH-GGZ evalueerde de klachten van de patiënt regelmatig met behulp van een vragenlijst en verleende terugvalpreventie. De primaire uitkomstmaat was de ernst van de angstklachten, gemeten met de Beck Anxiety Inventory (BAI) gedurende één jaar.

RESULTATEN Aan het onderzoek namen 180 patiënten deel met een paniekstoornis of een gegeneraliseerde angststoornis, 114 in de interventiegroep en 66 in de controlegroep. Getuige de BAIscores op 3, 6, 9 en 12 maanden na aanvang bleek collaborative stepped care significant effectiever dan de gebruikelijke huisartsenzorg. Het grootste verschil in de daling van deze score werd gevonden na 12 maanden (-6,85 punten; 95\% $\mathrm{BI}-10,13$ tot $-3,55)$.

CONCLUSIE Collaborative stepped care is een effectieve methode om patiënten met paniekstoornis en/of gegeneraliseerde angststoornis te behandelen in de huisartsenpraktijk.

GZZ inCeest, partner van VUmc, Postbus 74077, 1070 BB Amsterdam: dr. A.D.T. Muntingh, psycholoog en post-doc onderzoeker. Universiteit van Tilburg, afdeling Tranzo, Centrum voor Lichaam, Geest en Gezondheid, Tilburg: prof.dr. C.M. van der Feltz-Cornelis, psychiater, hoogleraar Sociale Psychiatrie (tevens GCz Breburg, Tilburg en Trimbos-instituut, Utrecht); VUmc, afdeling Huisarts geneeskunde en EMCO+-Instituut, Amsterdam: dr. H.W.J. van Marwijk, huisarts, senior onderzoeker. LUMC, afdeling Psychiatrie, Leiden: prof.dr. Ph. Spinhoven, hoogleraar Klinische Psychologie (tevens Leiden Universiteit, faculteit Sociale Wetenschappen). Radboudumc, afdeling Eerstelijnsgeneeskunde, Nijmegen: prof.dr. W.J.J. Assendelft, hoogleraar Huisartsgeneeskunde. LUMC, afdeling Public Health en Eerstelijnsgeneeskunde, Leiden: dr. M.W.M. de Waal, senior onderzoeker. VUmc, afdeling Psychiatrie en het EMCO+ Instituut, Amsterdam: prof.dr. A.J.L.M. van Balkom, psychiater en hoogleraar Evidence Based Psychiatrie • Correspondentie:

a.muntingh@ggzingeest.nl• Mogelijke belangenverstrengeling: het onderzoek werd gefinancierd door ZonMw (projectnummer: 170882701).

Dit onderzoek werd eerder gepubliceerd als: Muntingh A, Van der Feltz-Cornelis C, Van Marwijk H, Spinhoven P, Assendelft W, De Waal M, et al. Effectiveness of collaborative stepped care for anxiety disorders in primary care: a pragmatic cluster randomised controlled trial. Psychother Psychosom 2014;83:37-44. Publicatie gebeurt met toestemming van de uitgever.

\section{INLEIDING}

$\mathrm{D}^{\circ}$ paniekstoornis en de gegeneraliseerde angststoornis zijn twee angststoornissen die geregeld voorkomen in de huisartsenpraktijk. ${ }^{1}$ Beide stoornissen zijn invaliderend en bij ongeveer tweederde van de patiënten hebben ze een chronisch beloop. ${ }^{2}$ De meeste patiënten met een chronische angststoornis worden behandeld in de huisartsenpraktijk, ${ }^{3}$ maar het blijkt lastig de daarvoor ontwikkelde evidence-based interventies goed toe te passen. Hier zijn verschillende redenen voor: huisartsen zijn vaak niet voldoende ervaren in cognitieve gedragstherapie of hebben te weinig tijd, patiënten hebben bezwaren tegen medicatie of tegen een doorverwijzing naar de psycholoog, en de samenwerking van de huisarts met andere hulpverleners of instellingen is niet altijd goed geregeld. ${ }^{4-7}$ Bovendien is het in de huidige behandelpraktijk niet gebruikelijk om een angststoornis te benaderen als een chronische aandoening, terwijl zij dat meestal wel is.

Collaborative care is een behandelmodel voor psychische stoornissen dat gebaseerd is op een model uit de chronische somatische zorg. In het collaborative-caremodel werken verschillende hulpverleners samen (huisarts, praktijkondersteuner, psychiater), ${ }^{8}$ met de praktijkondersteuner geestelijke gezondheidszorg (POH-GGZ) in de rol van care manager. De POH-GGZ geeft de patiënt uitleg over de klachten en de behandeling, verleent psychologische zorg op basis van wetenschappelijk onderbouwde protocollen en evalueert de voortgang van de behandeling met de patiënt. De huisarts en de POH-GGZ kunnen aan een psychiater advies vragen over de patiënt of de behandeling.

Met collaborative care zijn goede resultaten geboekt in de behandeling van depressie, ${ }^{9}$ voornamelijk in de Verenig-

\section{Wat is bekend?}

- Collaborative care is een effectieve methode voor de behandeling van depressie in de huisartsenpraktijk en lijkt ook veelbelovend bij angststoornissen.

- Stepped care is in de NHG-Standaard Angst opgenomen en kan een aanvulling zijn op collaborative care.

- Collaborative stepped care bestaat uit het stapsgewijs toepassen van wetenschappelijk onderbouwde interventies, het monitoren van klachten en terugvalpreventie door een team bestaande uit huisarts, $\mathrm{POH}-\mathrm{GGZ}$ en psychiater.

\section{Wat is nieuw?}

- Na de goede ervaringen bij depressie blijkt collaborative care in de huisartsenpraktijk ook bij angststoornissen tot betere uitkomsten te leiden dan de gebruikelijke zorg.

- De combinatie van collaborative care met stepped care lijkt goed te werken.

- De POH-GGZ, mits goed getraind, kan een belangrijke rol spelen in het behandelen van patiënten met angststoornissen binnen de basis-GGZ. 


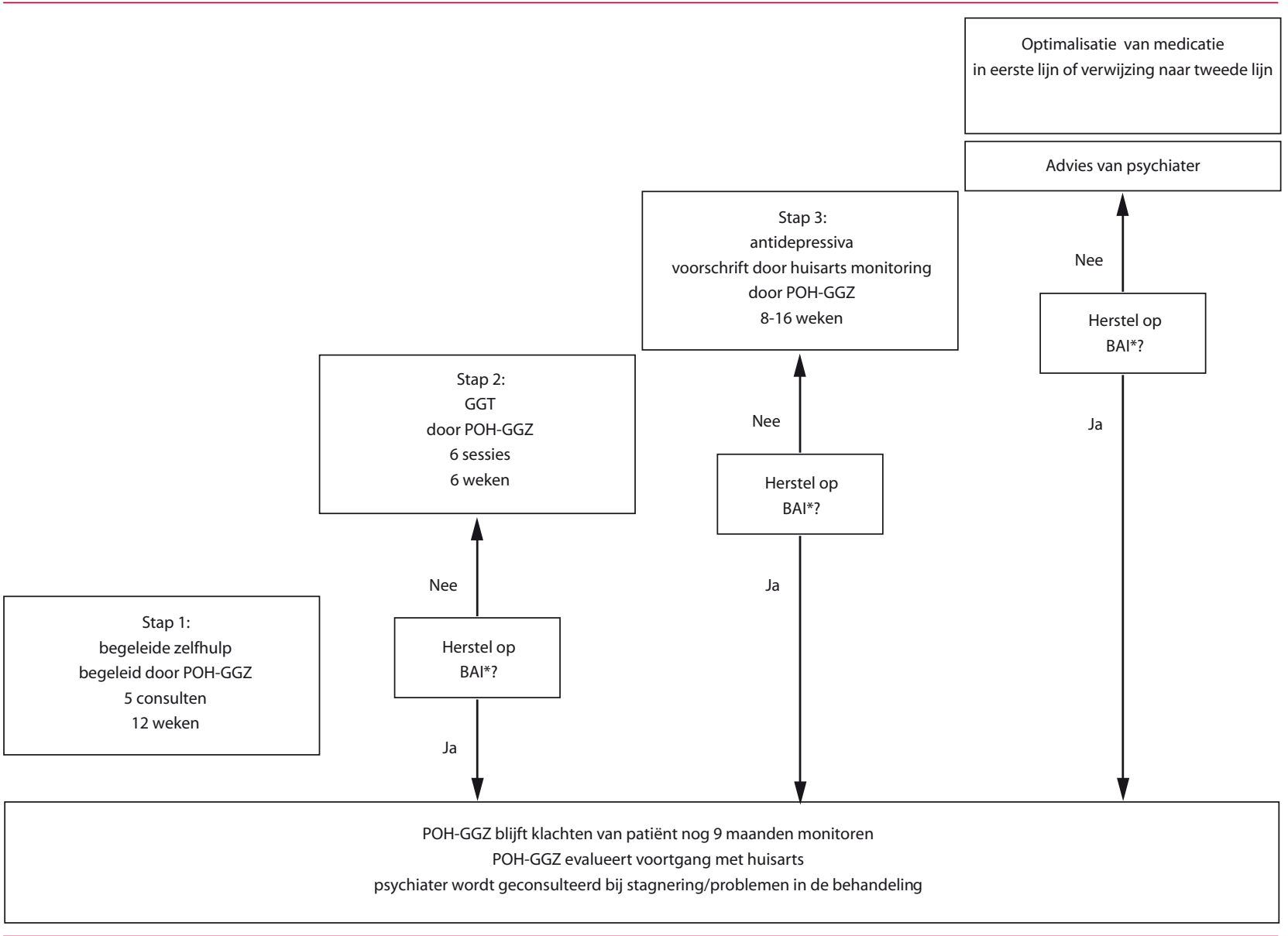

BAI = Beck Anxiety Inventory; CGT = cognitieve gedragstherapie; POH-GGZ = praktijkondersteuner huisartsenpraktijk geestelijke gezondheidszorg

* Herstel is gedefinieerd als een score $\leq 11$ op de vragenlijst.

de Staten maar ook in Nederland. ${ }^{10}$ Het model lijkt ook voor angststoornissen veelbelovend, ${ }^{9,11}$ maar het aantal onderzoeken is beperkt. In een recent Nederlands onderzoek naar collaborative care voor depressie, angststoornissen en stress is een stapsgewijze aanpak gebruikt: stepped care, met goede resultaten op de korte termijn. ${ }^{12}$ Stepped care kan de zorg voor patiënten met een angststoornis efficiënter maken en is opgenomen in de NHG-standaard Angst. ${ }^{13}$

Wij ontwikkelden een collaborative stepped care model dat bestaat uit drie opeenvolgende behandelstappen: begeleide zelfhulp, kortdurende cognitieve gedragstherapie en antidepressiva, interventies die op zichzelf al effectief gebleken zijn bij de behandeling van paniekstoornis en gegeneraliseerde angststoornis in de huisartsenpraktijk..$^{14-15}$ De POH-GGZ begeleidt de zelfhulp, geeft de cognitieve gedragstherapie, evalueert regelmatig de angstklachten en verleent terugvalpreventie tot negen maanden na het einde van de behandeling. Alle patiënten beginnen in principe bij stap één en krijgen de volgende stap alleen aangeboden als zij niet herstellen, al kunnen de hulpverleners hiervan afwijken indien zij daar aanleiding toe zien. Tijdens de behandeling houdt de
POH-GGZ nauw contact met de huisarts over de voortgang, en de huisarts schrijft indien nodig antidepressiva voor volgens de Multidisciplinaire richtlijn angstsstoornissen. ${ }^{16}$ De POH-GGZ en de huisarts beschikken over een consulent-psychiater aan wie zij advies kunnen vragen over de patiënt of de behandeling.

\section{METHODE}

\section{Onderzoeksontwerp}

Dit clustergerandomiseerde, gecontroleerde onderzoek vond plaats tussen september 2008 en maart 2011 in 43 huisartsenpraktijken in de regio Zuid-Holland-Noord. Aan het onderzoek namen 31 POH's-GGZ deel, allen verbonden aan één of twee huisartsenpraktijken en grotendeels geworven via het Leids Eerstelijns Onderzoeksnetwerk (LEON). De POH's-GCZ werden via loting ingedeeld in één van de twee onderzoeksgroepen: de interventiegroep (16 POH's-GCZ), die collaborative stepped care verleende, of de controlegroep (15 POH's-GCZ), die de gebruikelijke zorg verleende. De POH's-GGZ en de huisartsen in de interventiegroep kregen een training in collaborative stepped care, en daarnaast hadden zij de mogelijkheid advies te vragen aan een psychiater (zes psychiaters waren 
Tabel 1 Kenmerken van de deelnemers in de interventiegroep (collaborative stepped care) en de controlegroep (gebruikelijke zorg) bij aanvang

\begin{tabular}{|c|c|c|c|c|}
\hline & $\begin{array}{l}\text { Collabora- } \\
\text { tive stepped } \\
\text { care } \\
(n=114)\end{array}$ & $\begin{array}{l}\text { Gebruikelijke } \\
\text { zorg } \\
(n=66)\end{array}$ & $\begin{array}{l}\text { Totaal } \\
(\mathrm{n}=180)\end{array}$ & $\begin{array}{l}\text { p-waarde* } \\
x^{2}\end{array}$ \\
\hline Leeftijd, gemiddelde (SD) & $45,0(15,1)$ & $49,0(16,0)$ & $46,5(15,5)$ & 0,09 \\
\hline Sekse, \% vrouw & 72,8 & 60,6 & 68,3 & 0,09 \\
\hline Niet-Nederlandse afkomst, \% & 10,6 & 10,8 & 10,7 & 0,50 \\
\hline Opleidingsniveau hbo/wo, \% & 18,4 & 23,1 & 20,1 & 0,71 \\
\hline Getrouwd of samenlevend, \% & 57,5 & 63,1 & 59,6 & 0,23 \\
\hline $\begin{array}{l}\text { BAl-score bij aanvang, gemiddelde } \\
(\mathrm{SD})^{\dagger}\end{array}$ & $24,6(11,5)$ & $20,0(11,3)$ & $22,1(11,6)$ & 0,01 \\
\hline Primaire diagnose, \% & & & & 0,94 \\
\hline - paniekstoornis & 42,1 & 43,9 & 42,8 & \\
\hline - gegeneraliseerde angststoornis & 28,1 & 25,8 & 27,2 & \\
\hline $\begin{array}{l}\text { - paniekstoornis en gegeneraliseerde } \\
\text { angststoornis }\end{array}$ & 29,8 & 30,3 & 30,0 & \\
\hline Comorbide depressie, \% & 29,8 & 33,3 & 31,1 & 0,62 \\
\hline $\begin{array}{l}\text { Al eerder psychologische behandeling } \\
\text { gehad, \% }\end{array}$ & 56,9 & 70,5 & 61,8 & 0,08 \\
\hline $\begin{array}{l}\text { Gebruik van antidepressiva bij } \\
\text { aanvang, \% }\end{array}$ & 21,9 & 38,3 & 27,9 & 0,02 \\
\hline $\begin{array}{l}\text { Aantal chronische ziekten, gemiddelde } \\
\text { (SD) }\end{array}$ & $1,4(1,6)$ & $1,6(1,5)$ & $1,4(1,5)$ & 0,35 \\
\hline
\end{tabular}

* Significante waarden $(<0,05)$ zijn vetgedrukt.

† Ongecorrigeerde score. uit begeleide zelfhulp. Hierbij ontving de patiënt een zelfhulpboek met begeleiding door de $\mathrm{POH}-\mathrm{GGZ}$ in vijf korte consulten van elk 20-30 minuten. Het zelfhulpboek bevatte achtergrondinformatie over angstklachten en oefeningen uit de cognitieve gedragstherapie. ${ }^{19}$ Stap 2 bestond uit zes sessies cognitieve gedragstherapie, gegeven door de $\mathrm{POH}-\mathrm{GCZ}$ op basis van een protocol. In stap 3 schreef de huisarts antidepressiva voor, volgens een op wetenschappelijke richtlijnen gebaseerd algoritme voor het starten, ophogen en switchen van medicatie. Na elke stap evalueerde de $\mathrm{POH}-\mathrm{GCZ}$ het effect van de behandeling met behulp van de Beck Anxiety Inventory (BAI). ${ }^{20}$ Deze vragenlijst bestaat uit 21 vragen over symptomen van angst, met een totaalscore die kan variëren tussen o (geen angstklachten) en 63 (zeer ernstige angstklachten). Het doel van iedere stap was herstel, dat wil zeggen een 'normale' angstscore (BAI-score $\leq 11)$. Als een patiënt niet herstelde, werd de volgende stap ingezet. Was een patiënt eenmaal hersteld, dan belde de POH-GGZ in de negen maanden na de behandeling nog een aantal keren op om terugval te voorkomen.

\section{Gebruikelijke zorg}

De huisartsen in de controlegroep boden de gebruikelijke zorg, met alle opties die zij normaal gesproken ook hebben, zoals het zelf voeren van een aantal gesprekken, medicatie voorschrijven of verwijzen naar een eerstelijnspsycholoog of een GGZ-instelling. Ook konden zij patiënten verwijzen naar een $\mathrm{POH}-\mathrm{GGZ}$, die in alle controlepraktijken aanwezig was maar geen aanvullende training in collaborative stepped care had gekregen.

beschikbaar voor consultatie). Voor het uitgebreide onderzoeksdesign verwijzen we naar onze eerder verschenen artikelen over deze trial. ${ }^{7-18}$

\section{Collaborative stepped care}

De collaborative stepped care die in de interventiegroep gegeven werd, omvatte drie stappen [figuur 1]. Stap 1 bestond

Figuur 2 Verloop van de angstklachten (BAI-score) gedurende een jaar

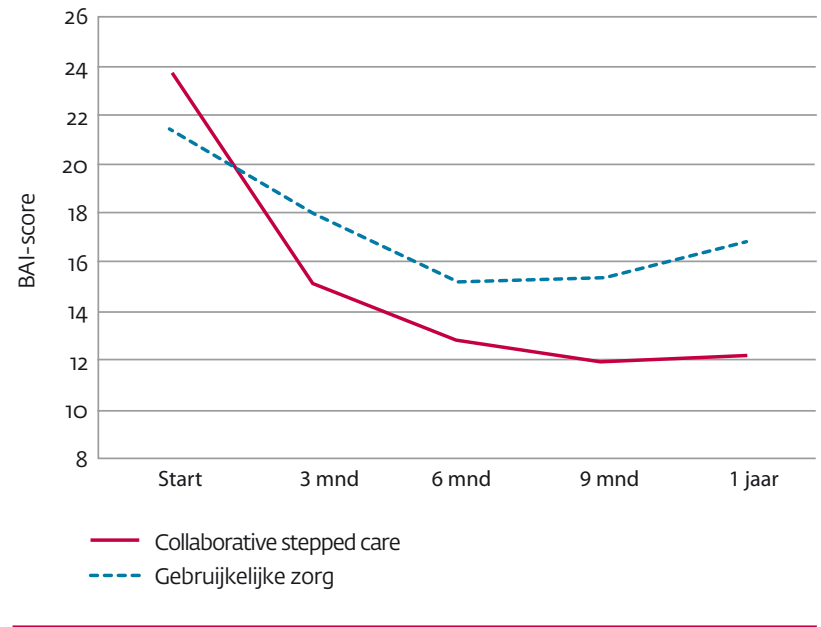

\section{Deelnemers}

Huisartsen konden patiënten van 18 jaar of ouder met een vermoedelijke angststoornis aanmelden voor het onderzoek. Daarnaast selecteerde een onderzoeksassistent patiënten uit het elektronisch dossier van de huisarts op basis van risicofactoren voor angststoornissen. ${ }^{21} \mathrm{Bij}$ alle patiënten die aan de onderzoekscriteria voldeden en die wilden meewerken aan het onderzoek namen geblindeerde onderzoeksassistenten het Mini Internationaal Neuropsychiatrisch Interview (MINI) af, ${ }^{22}$ om vast te stellen of er sprake was van een paniekstoornis of een gegeneraliseerde angststoornis. Patiënten die een psychotische of bipolaire stoornis hadden, suïcidaal waren, afhankelijk waren van middelen of de Nederlandse taal onvoldoende beheersten, konden niet meedoen met het onderzoek. Alle andere (psychiatrische) comorbiditeit was toegestaan.

\section{Metingen en analyse}

De deelnemende patiënten werden twaalf maanden lang gevolgd, waarin zij in totaal vijf keer een BAI-vragenlijst invulden (bij aanvang en daarna iedere drie maanden). De primaire uitkomstmaat was de afname van angstklachten zoals gemeten met de BAI. ${ }^{20}$

Wij berekenden de verschillen in BAI-scores tussen de beide onderzoeksgroepen met behulp van multilevel lineaire regressieanalyse, gecorrigeerd voor mogelijke bias die samen- 
hangt met de clusterrandomisatie. Uitgebreide informatie over de analyses is te vinden in onze eerder verschenen artikelen. ${ }^{17-18}$

\section{RESULTATEN}

Wij includeerden 180 patiënten, 114 in de interventiegroep en 66 in de controlegroep. Dit verschil in aantal werd veroorzaakt doordat huisartsen in de interventiegroep meer patiënten aanmeldden voor het onderzoek. Bij aanvang waren er geen significante verschillen tussen de patiënten in de interventiegroep en die in de controlegroep, behalve op de BAI-score en het gebruik van antidepressiva [tabel 1]. Hiervoor is gecorrigeerd in de analyses.

In beide onderzoeksgroepen namen de angstklachten significant af bij de vervolgmetingen [figuur 2]. Bij collaborative stepped care was deze daling significant sterker dan bij de gebruikelijke zorg: de daling van de geschatte gemiddelde BAI-score ten opzichte van de aanvangsmeting was in de interventiegroep na drie maanden $-5,11$ punten sterker (95\%-betrouwbaarheidsinterval (95\%-BI -8,28 tot-1,94), na zes maanden $-4,65$ punten ( $95 \% \mathrm{BI}-7,93$ tot $-1,38$ ), na negen maanden $-5,67$ punten ( $95 \%$ BI $-8,97$ tot $-2,36$ ) en na twaalf maanden $-6,84$ punten $(95 \% \mathrm{BI}-10,13$ tot $-3,55)$ [tabel 2].

Van de deelnemers die collaborative stepped care kregen, doorliep 50\% alleen stap 1, 10\% stap 1 en 2 , en $18 \%$ stap 1 en 3 . De overige $22 \%$ stopte vroegtijdig met de behandeling. Op basis van het herstelcriterium hadden meer patiënten (27\%) moeten doorstromen naar stap 2.

Van de deelnemers die gebruikelijke zorg ontvingen, voerde $22 \%$ gesprekken met huisarts, POH-GCZ of psycholoog, kreeg 36\% antidepressiva en werd $18 \%$ verwezen naar de specialistische GCZ. De overige $24 \%$ kreeg of wilde geen hulp voor de angstklachten.

\section{DISCUSSIE}

Ons onderzoek wijst uit dat collaborative stepped care in de huisartsenpraktijk effectiever is dan de gebruikelijke zorg. Dit resultaat komt redelijk overeen met de resultaten van Amerikaans en Nederlands onderzoek naar de effectiviteit van col-

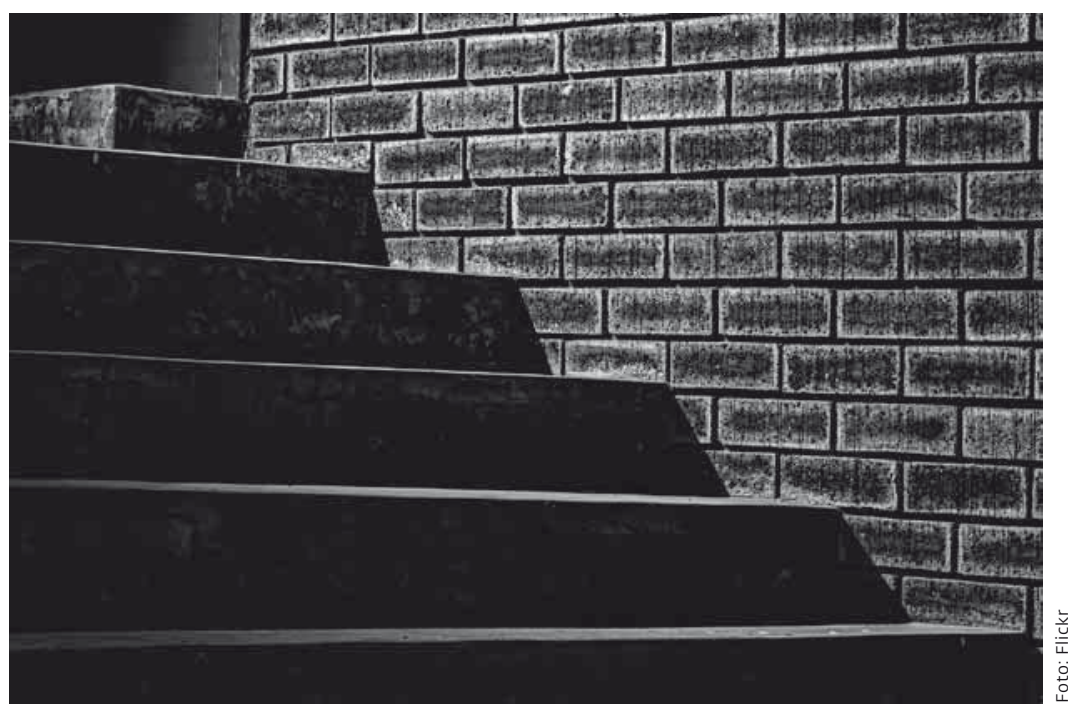

laborative care bij depressie, stress en angststoornissen.9-12,23-26 In vergelijking met een Nederlands onderzoek naar stepped care in de huisartsenpraktijk ${ }^{27}$ vonden wij een groter effect, wat verklaard zou kunnen worden door de grotere rol van de $\mathrm{POH}-\mathrm{GCZ}$ en de samenwerking met een consulent-psychiater in ons onderzoek. Opvallend was dat in de groep die gebruikelijke zorg kreeg slechts enkele patiënten werden behandeld door de (niet voor het onderzoek getrainde) POH-GGZ.

\section{Sterke en zwakke punten}

Een sterk punt van dit onderzoek is dat de behandeling werd uitgevoerd door professionals die in de praktijk werken, waardoor de resultaten de dagelijkse praktijk goed benaderen. Een beperking is dat de clusterrandomisatie zorgde voor een scheve verdeling in het aantal aanmeldingen over beide onderzoeksarmen, en dat er sprake was van een significant verschil in angstscore en antidepressivagebruik bij aanvang. Voor deze verschillen is gecorrigeerd en in een analyse met alleen de patiënten die via screening waren geworven vonden we vergelijkbare resultaten. Selectiebias is echter niet volledig uit te sluiten. Een tweede beperking is dat het inter-

Tabel 2 Ontwikkeling van de geschatte gemiddelde BAI-score bij collaborative stepped care versus gebruikelijke zorg gedurende twaalf maanden

\begin{tabular}{|c|c|c|c|c|c|c|c|c|c|}
\hline \multirow[t]{2}{*}{ Meting } & \multicolumn{2}{|c|}{$\begin{array}{l}\text { Collaborative stepped care } \\
(n=114)\end{array}$} & \multicolumn{2}{|c|}{ Gebruikelijke zorg $(n=66)$} & \multicolumn{5}{|c|}{ Collaborative stepped care versus gebruikelijke zorg } \\
\hline & $M^{*}$ & $95 \%-B I$ & $\mathbf{M}^{*}$ & $95 \%-B I$ & $d^{+}$ & $95 \%-B I$ & $\Delta^{\ddagger}$ & $95 \%-B \mid$ & p-waarde \\
\hline Aanvang & 23,7 & 20,6 tot 26,7 & 21,4 & 18,7 tot 24,1 & & & & & \\
\hline 3 maanden & 15,1 & 12,1 tot 18,1 & 18,0 & 15,0 tot 20,9 & 0,23 & 0,01 tot 0,45 & $-5,1$ & $-8,3$ tot $-1,9$ & 0,001 \\
\hline 6 maanden & 12,8 & 9,8 tot 15,8 & 15,3 & 12,6 tot 17,8 & 0,20 & $-0,04$ tot 0,44 & $-4,7$ & $-7,9$ tot $-1,4$ & 0,01 \\
\hline 9 maanden & 12,0 & 8,9 tot 15,0 & 15,4 & 12,7 tot 18,0 & 0,28 & 0,04 tot 0,52 & $-5,7$ & $-9,0$ tot $-2,4$ & 0,001 \\
\hline 12 maanden & 12,2 & 9,2 tot 15,2 & 16,8 & 14,2 tot 19,4 & 0,38 & 0,14 tot 0,62 & $-6,8$ & $-10,1$ tot $-3,6$ & 0,001 \\
\hline
\end{tabular}

"M = gemiddelde score, geschat met multilevel regressieanalyse op basis van intention to treat, gecorrigeerd met propensity scores en voor de ernst van de angst bij aanvang.

$\dagger d=$ effectgrootte, berekend door het verschil in gemiddelde scores te delen door de gepoolde standaarddeviatie.

$\ddagger \Delta=$ verschil in afname van de BAI-score.

$\int$ De $\mathrm{p}$-waarde voor $\Delta$ is berekend met de Wald-test; een waarde $<0,05$ duidt op een significant verschil. 
ventieprogramma van collaborative stepped care niet altijd gevolgd werd zoals het bedoeld was. Vooral de overgangen naar stap 2 en stap 3 waren niet altijd conform de instructie. Bij goede adherentie aan het behandelmodel zouden de effecten misschien nog beter geweest zijn. Het is belangrijk de voortgang van de patiënten actief te volgen en hen te motiveren tot een vervolginterventie volgens het behandelmodel wanneer nodig.

\section{Aanbevelingen voor praktijk en beleid}

Collaborative stepped care is een veelbelovende, effectieve interventie die meerwaarde kan hebben voor de Nederlandse huisartsenpraktijk. De inzet van een POH-GCZ en de mogelijkheid tot consultatie van een psychiater maken dat de in dit onderzoek gebruikte methode van collaborative stepped care zeer goed past binnen de kaders van de huisartsenzorg. Wel is het belangrijk dat de $\mathrm{POH}-\mathrm{GCZ}$ in staat is de interventie op de juiste manier uit te voeren en dat er goede praktische en financiële mogelijkheden zijn om een psychiater te consulteren.

\section{DANKBETUIGING}

Wij danken Rivierduinen en hun professionals, het LEONnetwerk van het LUMC en alle deelnemende huisartsenpraktijken en patiënten voor hun inzet. Tevens danken we Joske Vink, Daniëlle Volker, Tessa Bouman, Tessa Bouwmeester, Eric de Heer, Paul Bras en Berdien Palland voor hun ondersteuning bij de gegevensverzameling. Tot slot danken we Herman Adèr voor zijn ondersteuning bij de data-analyse.

\section{LITERATUUR}

1 Donker, T, Comijs, H, Cuijpers, P, Terluin, B, Nolen, W, Zitman F, et al. The validity of the Dutch K10 and extended K10 screening scales for depressive and anxiety disorders. Psychiatry Res 2010;176:45-50.

2 Yonkers KA, Bruce SE, Dyck IR, Keller MB. Chronicity, relapse, and illness-course of panic disorder, social phobia, and generalized anxiety disorder: findings in men and women from 8 years of follow-up. Depress Anxiety 2003;17:173-9.

3 Verhaak PF, Prins MA, Spreeuwenberg P, Draisma S, Van Balkom TJ, Bensing JM, et al. Receiving treatment for common mental disorders. Gen Hosp Psychiatry 2009;31:46-55.

4 Van Marwijk, H. How to improve mental health competency in general practice training? A SWOT analysis. Eur J Gen Pract 2004;10:61-5.

5 Prins MA, Verhaak PF, Van der Meer K, Penninx BW, Bensing JM. Primary care patients with anxiety and depression: need for care from the patient's perspective. J Affect Disord 2009;119,163-71.

6 Van Rijswijk E, Van Hout H, Van de Lisdonk E, Zitman F, Van Weel C. Barriers in recognising, diagnosing and managing depressive and anxiety disorders as experienced by Family Physicians; a focus group study. BMC Fam Pract 2009;10:52.

7 Muntingh A, Hermens M, Franx G, Van Splunteren P, Nuijen J. Werkelijke en wenselijke eerstelijns depressiezorg: Resultaten van een verkennend onderzoek. Trendrapportage GGZ 2012 Deel 3B. Utrecht: Trimbos-instituut, 2012.
8 Katon W, Unützer J, Wells K, Jones L. Collaborative depression care: history, evolution and ways to enhance dissemination and sustainability. Gen Hosp Psychiatry 2010;32:456-64.

9 Archer J, Bower P, Gilbody S, Lovell K, Richards D, Gask L, et al. Collaborative care for depression and anxiety problems. Cochrane Database Syst Rev 2010;10:CD006525.

10 Huijbregts KM, De Jong FJ, Van Marwijk HWJ, Beekman ATF, HakkaartRoijen L, Van der Feltz-Cornelis CM. Collaborative care voor depressieve patiënten. Huisarts Wet 2013;56:210-3.

11 Smolders M, Laurant M, Roberge P, Van Balkom A, Van Rijswijk E, Bower P, et al. Knowledge transfer and improvement of primary and ambulatory care for patients with anxiety. Can J Psychiatry 2008; 53:277-93.

12 Oosterbaan DN, Verbraak MJPM, Terluin B, Hoogendoorn AW, Peyrot, WJ, Muntingh ADT, et al. Collaborative stepped care versus care as usual in patients with common mental disorders: an 8-month, cluster-randomised controlled trial in primary care and specialised mental healthcare. $\mathrm{Br}$ J Psychiatry 2013;203:132-9.

13 Hassink-Franke LJA, Terluin B, Van Heest FB, Hekman J, Van Marwijk HWJ, Van Avendonk MJP. NHG-Standaard Angst (tweede herziening). Huisarts Wet 2012;2:68-77.

14 Van Boeijen CA, Van Oppen P, Van Balkom AJ, Visser S, Kempe PT, Blankenstein $\mathrm{N}$, et al. Treatment of anxiety disorders in primary care practice: a randomised controlled trial. Br J Gen Pract 2005;55:763-9.

15 Van der Feltz-Cornelis CM, Van Oppen P, Adèr H, Van Dyck R. Randomised controlled trial of a collaborative care model with psychiatric consultation for persistent medically unexplained symptoms in general practice. Psychother Psychosom 2006;75:282-9.

16 Landelijke Stuurgroep Multidisciplinaire Richtlijnontwikkeling in de GCZ. Multidisciplinaire Richtlijn Angststoornissen (tweede revisie). Utrecht: Trimbos-instituut, 2010.

17 Muntingh AD, Van der Feltz-Cornelis CM, Van Marwijk HW, Spinhoven P, Assendelft WJ, De Waal MW, et al. Collaborative stepped care for anxiety disorders in primary care: aims and design of a randomized controlled trial. BMC Health Services Research 2009;9:159.

18 Muntingh A, Van der Feltz-Cornelis C, Van Marwijk H, Spinhoven P, Assendelft W, De Waal M, Adèr H, Van Balkom A. Effectiveness of collaborative stepped care for anxiety disorders in primary care: a pragmatic clus ter randomised controlled trial. Psychother Psychosom 2014;83:37-44.

19 Van Boeijen, CA. Handboek begeleide zelfhulp: Overwinnen van angstklachten. Apeldoorn: Van Boeijen, 2007.

20 Beck AT, Epstein N, Brown G, Steer RA. An inventory for measuring clinical anxiety: psychometric properties. J Consult Clin Psychol 1988;56:893-7.

21 Kroenke K, Spitzer RL, Williams JB, Linzer M, Hahn SR, deGruy FV 3rd, et al. Physical symptoms in primary care: Predictors of psychiatric disorders and functional impairment. Arch Fam Med 1994;3:774-9.

22 Van Vliet IM, Leroy H, Van Megen HJM. Het Mini Internationaal Neuropsychiatrisch Interview (MINI): een kort gestructureerd diagnostisch interview voor DSM-IV en ICD-10 psychiatrische stoornissen. Leiden: LUMC, 2000.

23 Roy-Byrne PP, Katon W, Cowley DS, Russo J. A randomized effectiveness trial of collaborative care for patients with panic disorder in primary care. Arch Gen Psychiatry 2001;58:869-76.

24 Roy-Byrne PP, Craske MG, Stein MB, Sullivan G, Bystritsky A, Katon W, et al. A randomized effectiveness trial of cognitive-behavioral therapy and medication for primary care panic disorder. Arch Gen Psychiatry 2005;62:290-8.

25 Rollman BL, Belnap BH, Mazumdar S, Houck PR, Zhu F, Gardner W, et al. A randomized trial to improve the quality of treatment for panic and generalized anxiety disorders in primary care. Arch Gen Psychiatry 2005;62:1332-41.

26 Roy-Byrne P, Craske MG, Sullivan G, Rose RD, Edlund MJ, Lang AJ, et al. Delivery of evidence-based treatment for multiple anxiety disorders in primary care: a randomized controlled trial. JAMA 2010;303;1921-8.

27 Seekles W, Van Straten A, Beekman A, Van Marwijk H, Cuijpers P. Stepped care treatment for depression and anxiety in primary care: a randomized controlled trial. Trials 2011;12:171. 